\title{
Mechanisms of Intranephronal Proteinaceous Cast Formation by Low Molecular Weight Proteins
}

Paul W. Sanders, Beverly B. Booker, John B. Bishop, and Herbert C. Cheung

Nephrology Research and Training Center, Division of Nephrology, Department of Medicine, and Departments of Biochemistry and

Physics, University of Alabama at Birmingham, and Veterans Administration Medical Center, Birmingham, Alabama 35294

\section{Abstract}

Proteinaceous cast formation in the distal nephron of the kidney from low molecular weight proteinuria is a significant, but poorly characterized, cause of renal failure. To study this phenomenon, we: (a) microperfused the loop segment (LS) of rats in vivo with artificial tubule fluid (ATF) containing four different low molecular weight proteins, $0.01-50 \mathrm{mg} / \mathrm{ml}$, to detect alterations in LS function, and (b) examined the interaction between several proteins and Tamm-Horsfall glycoprotein (THP) in vitro with turbidity and dynamic light-scattering measurements. Perfusion of the LS for $<2$ min with castforming proteins (Bence Jones protein [BJP3] and myoglobin) decreased chloride absorption and elevated early distal tubule fluid (ED) $\left[\mathrm{Cl}^{-}\right]$, compared with results obtained with control perfusions that used ATF alone. BJP3 decreased chloride absorption in a concentration-dependent fashion. Perfusion with non-cast-forming proteins (albumin and BJP1) enhanced chloride absorption and decreased $\mathrm{ED}\left[\mathrm{Cl}^{-}\right]$. In vitro, proteins that had isoelectric points (pI) > 5.1 aggregated with THP. Aggregation was enhanced with increasing $[\mathrm{NaCl}]$ or $\left[\mathrm{CaCl}_{2}\right]$. $\mathrm{Al}$ bumin (pI 4.8) and $\beta$-lactoglobulin (pI 5.1) did not coprecipitate. The molecular size of THP alone increased when [ $\mathrm{NaCl}]$ $>80 \mathrm{mM}$.

Thus, cast-forming proteins aggregated with THP in vitro and caused in vivo $\mathrm{LS}$ dysfunction, which elevated $\mathrm{ED}\left[\mathrm{Cl}^{-}\right]$, facilitating aggregation. In contrast, non-cast-forming proteins either did not interact with THP or lowered ED $\left[\mathrm{Cl}^{-}\right]$, which did not provide an environment for aggregation. Altered LS function and interaction of some proteins with THP were related to different physicochemical properties of the proteins and independently contributed to the formation of proteinaceous casts in the kidney. (J. Clin. Invest. 1990. 85:570-576.) cast nephropathy $\bullet$ protein nephrotoxicity $\bullet$ Bence Jones proteins • immunoglobulin light chains • myeloma kidney

\section{Introduction}

Renal failure from low molecular weight proteins (LMWP) ${ }^{1}$ is a common clinical problem. In one study, renal lesions from

Portions of this work have been presented at the 1989 annual session of the American Federation for Clinical Research and the 6th International Symposium of Nephrology at Montecatini, and have been published in abstract form [1989. Clin. Res. 37:500A. (Abstr.)].

Address reprint requests to Dr. P. W. Sanders, Division of Nephrology, Department of Medicine, 6th Fl., Zeigler Bldg., University of Alabama at Birmingham, Birmingham, AL 35294.

Received for publication 3 August 1989 and in revised form 29 September 1989.

1. Abbreviations used in this paper: ALB, albumin; ATF, artificial tubule fluid; BJP, Bence Jones protein; BLG, $\beta$-lactoglobulin; BW,

The Journal of Clinical Investigation, Inc.

Volume 85, February 1990, 570-576 deposition of monoclonal immunoglobulin light chains, which are also known as Bence Jones proteins (BJP), were found in over $2 \%$ of renal biopsies (1). For BJPs, hemoglobin, and myoglobin (MYG), the tubulointerstitium is the usual site of damage (2-5). Although proximal tubule injury occurs with reabsorption and catabolism of some LMWPs (6-8), a major morphologic pattern of tubule damage in patients $(2,3,9-11)$ and several experimental models of LMWP nephrotoxicity $(5,10$, 12-14) consists of casts of LMWPs in the lumen of the distal nephrons.

Protein casts suggest an important role of intranephronal obstruction in the pathogenesis of renal failure from LMWPs. Physiologic evidence of intranephronal obstruction is provided by Weiss et al. (14), who demonstrated increased proximal tubule (PT) pressures and simultaneously reduced single nephron glomerular filtration rate with intravenous infusion of a human $\lambda$ BJP into rats. Because Tamm-Horsfall glycoprotein (THP) is identified in these casts $(2,3,9-11)$ and coprecipitates with some LMWPs in vitro (15), a role for THP in cast formation is postulated. Recently, we (8) have shown that some, but not all, nephrotoxic LMWPs precipitate and occlude the lumen of the distal nephron, which is the site of THP formation and secretion (16).

The purpose of this study was to examine in detail this process of intranephronal precipitation of LMWPs with in vivo microperfusion of the loop segment (LS) of the rat nephron and in vitro analysis of THP and LMWP interaction using turbidity and dynamic light-scattering measurements, that served as sensitive monitors of aggregation of these proteins in solution. Our studies demonstrated that, in this group of eight different proteins that were examined, protein cast formation was a function of both the isoelectric point (pI) of the LMWP and the ability of the LMWP to alter chloride absorption in the LS to produce the optimum environment for protein precipitation.

\section{Methods}

Protein preparation and analysis. THP was purified from the urine of a male volunteer using the original protocol of Tamm and Horsfall (17). Urine was collected and stored in the presence of thymol (J. T. Baker Chemical Co., Phillipsburg, NJ) at $4^{\circ} \mathrm{C}$ until processed. The protein was precipitated with the addition of $0.58-0.64 \mathrm{M} \mathrm{NaCl}$ to the urine, which was then stirred overnight at $4^{\circ} \mathrm{C}$. The precipitate was collected by centrifugation at $25,000 \mathrm{rpm}$ for 10-15 min (model PR-2 centrifuge; International Equipment Co., Needham Heights, MA) at $4^{\circ} \mathrm{C}$, then washed twice with $0.58 \mathrm{M} \mathrm{NaCl}$ and centrifuged. The protein was suspended in distilled water and dialyzed subsequently for $72 \mathrm{~h}$ at $4^{\circ} \mathrm{C}$

body weight; $d$, mean effective diameter, $D_{t}$, mean translational diffusion coefficient; ED, early distal tubule fluid; LMWP, low molecular weight proteins; LS, loop segment; LYZ, lysozyme; MYG, myoglobin; pI, isoelectric point; PT, proximal tubule; TALH, thick ascending limb; THP, Tamm-Horsfall glycoprotein. 
against distilled water using cellulose dialysis tubing (Spectropor membrane tubing; Fisher Scientific Co., Fair Lawn, NJ) that had a $12-14-\mathrm{kD}$ cutoff. The protein was lyophilized and stored at $-20^{\circ} \mathrm{C}$ until use. Purity was confirmed by electrophoresis on $10 \%$ polyacrylamide gels (Mini-Protean II Dual Slab Cell; Bio-Rad Laboratories, Richmond, CA) containing 0.1\% SDS-PAGE, using the discontinuous buffer system described by Laemmli (18). A single band of $\sim 80 \mathrm{kD}$ was identified after staining with $1 \%$ Coomassie blue (LKB Instruments, Inc., Bromma, Sweden). Ouchterlony double-diffusion analysis using goat antihuman uromucoid (Organon Teknika-Cappel, Durham, NC) demonstrated a single precipitin arc.

Three of the LMWPs were human BJPs (BJP1, BJP2, and BJP3) $-2 \kappa, 1 \lambda$-that were purified from the urine of patients who had multiple myeloma and renal failure using previously described techniques that included ammonium sulfate precipitation, ion exchange chromatography, and extensive dialysis (6). Rabbit myoglobin (MYG), lysozyme (LYZ), $\beta$-lactoglobulin (BLG) (all from Diversified Biotech, Newton Center, MA), and albumin (ALB) (bovine serum albumin, fraction V, essentially fatty acid-free; Sigma Chemical Co., St. Louis, MO) were also used. Cationic human serum ALB was a generous gift from Dr. John R. Hoyer (Children's Hospital of Philadelphia, Philadelphia, PA).

Ouchterlony double diffusion confirmed the isotype of the BJP using monoclonal and polyclonal antibodies to human $\kappa$ and $\lambda$ light chains (Behring Diagnostics, San Diego, CA). Molecular forms, molecular weights, purity, and $\mathrm{pI}$ of all of the proteins were determined with SDS-PAGE using both reducing and nonreducing conditions, gel filtration chromatography, and isoelectric focusing with Ampholine PAGplates, pH 3.5-9.5 (LKB Instruments, Inc.), as indicated (6, 8).

Animal preparation. Description of the anesthesia and surgical preparation of the rats used for in vivo microperfusion of the LS has been standardized in our laboratory and reported in detail $(6,8,19)$. Briefly, male Sprague-Dawley rats (Charles River Breeding Laboratories, Inc., Wilmington, MA, and National Cancer Institute, Frederick, $M D$ ), which weighed between 160 and $310 \mathrm{~g}$ (mean, $230 \pm 7 \mathrm{~g}$ ) and were maintained on standard rat chow (Prolab 1000; Agway Inc., Syracuse, NY) and tap water ad lib., were anesthetized with ethyl, 1-methylpropylthiobarbiturate (Inactin; BYK Gulden, FRG), $100 \mathrm{mg} / \mathrm{kg}$ body weight (BW), intraperitoneally. After placement on a servo-controlled heated table, tracheostomy and cannulation of the right external jugular vein were performed, followed by infusion of Ringer-bicarbonate with $2 \%$ polyfructosan (Inutest; Laevosan-Gesellschaft, Linz, Austria) at $1.2 \mathrm{ml} / 100 \mathrm{~g} \mathrm{BW} / \mathrm{h}$ after a $1-\mathrm{ml}$ bolus. The right femoral artery was cannulated to sample blood and monitor arterial pressure using a unigraph (model ICT-1H; Gilson Medical Electronics, Inc., Middleton, WI). The bladder was catheterized through a suprapubic route for urine collections. The left kidney was exposed through a subcostal incision and was placed in a Lucite ${ }^{\oplus}$ cup. A well was formed on the surface of the kidney with $4 \%$ agar and filled with water-equilibrated, warmed mineral oil.

$L S$ perfusion. After a 1-h equilibration period, arterial blood was sampled for determination of hematocrit, plasma osmolality, and plasma sodium, potassium, chloride, and protein concentrations, and microperfusion was begun. Perfusion of the LS of surface nephrons was performed as described by Booker and associates (20). The LS was defined as a short terminal section of the proximal convoluted tubule, the proximal straight tubule, the thin descending limb of Henle's loop, the medullary and cortical portions of the thick ascending limb (TALH), and a short initial segment of the distal convoluted tubule. A pipette filled with Food, Drug and Cosmetic green (No. 3-tinted; Keystone Aniline and Chemical Co., Chicago, IL), nonradioactive artificial tubule fluid (ATF) was inserted into a PT at random and a small bolus injected to identify both latest-surface proximal and earliest-surface distal sites. A perfusion pipette was inserted into the latest accessible surface PT and perfusion begun at $22 \mathrm{nl} / \mathrm{min}$ using a precalibrated microperfusion pump (World Precision Instruments Inc., New Haven, CT). The ATF consisted of (millimolar): $145 \mathrm{Na}^{+}, 5 \mathrm{~K}^{+}, 130 \mathrm{Cl}^{-}, 1$ $\mathrm{MgSO}_{4}, 10 \mathrm{NaHCO}_{3}, 1 \mathrm{NaH}_{2} \mathrm{PO}_{4}, 1 \mathrm{Ca}^{2+}$, and 4.2 urea. Extensively dialyzed $\left[{ }^{3} \mathrm{H}\right]$ methoxyinulin (New England Nuclear, Boston, MA) was added to yield $100-150 \mathrm{cpm} / \mathrm{nl}$ ATF. A pipette was inserted proximal to the perfusion pipette and a small cast of bone wax injected to obstruct the nephron completely. The segment proximal to this block was then vented. After 1-2 min of perfusion, a collection pipette was inserted into the surface distal tubule, an oil block was injected, and a complete timed collection obtained.

The effects of three test LMWPs (BJP1, BJP3, and MYG) and ALB were studied by adding them to ATF in concentrations that varied between 0.01 and $50 \mathrm{mg} / \mathrm{ml}$. In each animal, three tubules were perfused in both the experimental group, which used ATF containing a test LMWP, and the control group, which used ATF alone. The order used to obtain these collections was alternated daily. Tubule perfusions were accepted for study if they had calculated perfusion rates between 16 and $24 \mathrm{nl} / \mathrm{min}$ and collectate to perfusate inulin ratios $>1.0$ and $<3.0$. Results of suitable perfusions were averaged for each group and then compared. At the end of each experiment, the perfused tubules were dissected and examined with a dissecting microscope (model M3Z; Wild, Heerbrugg, Switzerland).

During the microperfusion period, two 30 -min inulin clearances were determined and, at the completion of the protocol, arterial blood was sampled for determination of hematocrit, plasma osmolality, and plasma sodium, potassium, chloride, and protein concentrations. Rats were considered unsuitable for study if the arterial pressure fell below $100 \mathrm{mmHg}$ or if the inulin clearance was $<400 \mu \mathrm{l} / \mathrm{min}$ per $100 \mathrm{~g} \mathrm{BW}$.

Turbidity measurements. THP, $0.1 \mathrm{mg} / \mathrm{ml}$, was mixed in solutions of $50 \mathrm{mM}$ Tris- $\mathrm{HCl}$, pH 7.0 that contained: $(a) \mathrm{NaCl}, 0,50,80,90$, 100 , or $125 \mathrm{mM}$; (b) $\mathrm{CaCl}_{2}, 2$ or $4 \mathrm{mM}$; or $(c) \mathrm{MgCl}_{2}, 2$ or $4 \mathrm{mM}$. Turbidity of these solutions was observed at a $90^{\circ}$ angle using a spectrofluorometer (model 650-40; Perkin-Elmer Corp., Norwalk, CT) at $500 \mathrm{~nm}$. After initial turbidity was determined, a test protein (ALB, BLG, LYZ, BJP1, BJP2, or BJP3) was added to the solution and the turbidity was recorded for $\sim 15 \mathrm{~min}$. Final concentration of the test proteins was $0.6 \mathrm{mg} / \mathrm{ml}$. In separate experiments, turbidity of these LMWP solutions in the absence of THP was determined. Turbidity measurements of MYG/THP solutions were not done because its red color interfered by absorbing light, but were easily examined visually for precipitate.

Dynamic light scattering. To examine in greater detail the interaction between THP and several LMWPs in buffered solutions containing various $[\mathrm{NaCl}]$, dynamic light scattering was employed to determine the mean diffusion coefficients (hence sizes) of macromolecules or aggregates in the solutions $(21,22)$. Solutions with the same chemical composition and protein concentrations as those used in the turbidity measurements (above) were used in these experiments, but the solutions were allowed to equilibrate for at least $2 \mathrm{~h}$ before measurements were made. To completely remove dust particles, which interfere with these measurements, the solutions were filtered with $0.45-\mu \mathrm{m}$ filters before mixing. The solutions contained THP alone or THP with BJP1, BJP3, ALB, and LYZ.

Dynamic light scattering was measured with a goniometer (model BI 200SM; Brookhaven Instrument Corp., Holtsville, NY) and digital correlator (model BI 2030; Brookhaven Instrument Corp.). The incident light was the 488-nm line generated from an argon ion laser (model 2020-05; Spectra Physics Inc., Piscataway, NJ) and the scattered light was detected by a photomultiplier tube at a fixed angle (60 or $90^{\circ}$ ) relative to the incident beam.

The theory of dynamic light scattering and its measurement by photon correlation spectroscopy has been described in standard treatises $(21,22)$. Information that is pertinent to the present study is summarized here. The intensity of light scattered from a solution of macromolecules fluctuates rapidly about some average value due to thermal motions of the molecules. The output of the instrument detector represents the intensity of the scattered light, $I(t)$. This signal was analyzed in the form of the intensity autocorrelation function, $G(\tau)$, given by (22):

$G(\tau)=\lim _{T \rightarrow \infty} \frac{1}{2 T} \int_{-T}^{T} I(t) I(t+\tau) \mathrm{d} t=\langle I(t) I(t+\tau)\rangle$, 
where $\tau$ is the signal delay time ( $\tau$ was varied relative to the size of the macromolecules in the test solution to produce a satisfactory exponentially decaying function) and $\langle>$ represents a time average.

Since the macromolecules under study were polydisperse, $G(\tau)$ was corrected with the method of cumulants (23) and expanded to the third moment $(23,24)$. These steps were carried out in the present work with the Brookhaven computer programs (Expsam 2.1 and BI 2030; Brookhaven Instrument Corp.). The mean translational diffusion coefficient $\left(D_{\mathrm{t}}\right)$ of the protein molecules was calculated from the autocorrelation function (22): $G(\tau)=1+(b) \exp \left(-2 D_{t} q^{2} \tau\right)$, where $b$ is a constant determined by the optics and geometry of the instrument and $q$ is the magnitude of the scattering vector, which is a function of the laser wavelength and scattering angle.

The effective diameter $(d)$ of the scattering macromolecule was calculated from the Stokes-Einstein relation (25): $d=k_{\mathrm{b}} \mathrm{T} / 3 D_{\mathrm{t}} \pi \eta$, where $k_{\mathrm{b}}$ is the Boltzmann constant, $T$ is the absolute temperature of the solution, and $\eta$ is the viscosity of the solvent.

Analytical methods. Detailed methodology for determination of inulin clearance, hematocrit, plasma osmolality, and plasma sodium, potassium, chloride, and protein concentrations has been reported (6). These values, which were obtained at the start and completion of the microperfusion period, were averaged for each rat.

Microanalysis was performed using previously described techniques (6). The volume of fluid collected from the LS was measured using constant bore glass tubing and a microslide comparator (Gaertner Scientific Co., Chicago, IL). Chloride concentrations of the perfusate and collectate samples were determined by electrometric titration (Picolab3; IDEA Computers, Inc., Richmond, TX). $\left[{ }^{3} \mathrm{H}\right]$ activities of measured volumes of the collected samples and perfusate were determined using a liquid scintillation counter (model 1214/1219 Rackbeta; LKB Instruments, Inc., Wallac, Turku, Finland). In vivo microperfusion rate and chloride absorption $\left(J_{\mathrm{Cl}}\right)$ were calculated using standard published equations (6).
Statistical analysis. All values were represented as mean \pm SEM. Comparisons between experimental and corresponding control groups were analyzed for statistical significance by the paired $t$ test, or analysis of variance where appropriate, with significance set at the 5\% level.

\section{Results}

LS perfusion studies. Mean systemic parameters of the 37 rats used in these studies were: hematocrit, $44 \pm 0 \%$; plasma sodium, $152 \pm 1 \mathrm{meq} / \mathrm{liter}$; plasma potassium, $5.0 \pm 0.2 \mathrm{meq} / \mathrm{liter}$; plasma chloride, $106 \pm 1 \mathrm{meq} /$ liter; plasma osmolality, $312 \pm 2$ mosmol $/ \mathrm{kg}$; and plasma protein, $4.7 \pm 0.0 \mathrm{~g} / \mathrm{dl}$. Mean arterial pressure during the collections averaged $122 \pm 2 \mathrm{mmHg}$. Average inulin clearance was $1071 \pm 67 \mu \mathrm{l} / \mathrm{min}$ per $100 \mathrm{~g} \mathrm{BW}$.

Four unique proteins, including ALB, MYG, BJP1, and BJP3, were used in these perfusion experiments (Table I). Mean calculated perfusion rates of the experimental and corresponding control (ATF) groups did not differ. Perfusion of the LS with BJP3 or MYG decreased $(P<0.05)$ chloride absorption and fractional chloride absorption and elevated $(P$ $<0.025) \mathrm{ED}\left[\mathrm{Cl}^{-}\right]$, compared with results obtained with control (ATF) perfusions. BJP3 decreased $\left[\mathrm{Cl}^{-}\right]$absorption in a concentration-dependent fashion (Fig. 1). Perfusion with ALB and BJP1 enhanced $(P<0.05)$ chloride absorption and decreased $(P<0.025)$ ED $\left[\mathrm{Cl}^{-}\right]$. Some variation in the control data occurred over the year of this study and justified obtaining control and experimental data from each rat. Dissection of the perfused nephrons at the end of the experiment did not demonstrate cast formation in the lumen of the LS after perfusion for $<2$ min with any of the LMWPs.

Table I. Summary of LS Perfusions

\begin{tabular}{|c|c|c|c|c|c|c|}
\hline Group & $\begin{array}{c}\text { Protein } \\
\text { concentration }\end{array}$ & $n$ & $\begin{array}{l}\text { Perfusion } \\
\text { rate }\end{array}$ & $\begin{array}{l}\text { Chloride } \\
\text { absorption }\end{array}$ & $\begin{array}{l}\text { Chloride } \\
\text { absorbed }\end{array}$ & $\begin{array}{l}\text { Early distal } \\
\text { fluid }\left[\mathrm{Cl}^{-}\right]\end{array}$ \\
\hline & $m g / m l$ & & $n l / \min$ & peq/min & $\%$ & meq/liter \\
\hline ALB & 1 & 5 & $18.7 \pm 1.2$ & $1,846 \pm 204$ & $76 \pm 3$ & $53 \pm 4$ \\
\hline ATF & & & $19.3 \pm 1.1$ & $1,298 \pm 175$ & $58 \pm 6$ & $85 \pm 9$ \\
\hline$\Delta$ & & & & $548 \pm 139^{*}$ & $18 \pm 1^{*}$ & $-32 \pm 27^{*}$ \\
\hline ATF & & & $21.6 \pm 0.9$ & $1,797 \pm 55$ & $68 \pm 3$ & $76 \pm 6$ \\
\hline$\Delta$ & & & & $274 \pm 94^{*}$ & $12 \pm 1^{*}$ & $-22 \pm 15^{*}$ \\
\hline BJP1 & 50 & 4 & $19.1 \pm 0.3$ & $1,659 \pm 135$ & $70 \pm 7$ & $51 \pm 10$ \\
\hline ATF & & & $21.1 \pm 0.8$ & $1,365 \pm 193$ & $53 \pm 6$ & $73 \pm 8$ \\
\hline$\Delta$ & & & & $294 \pm 121^{*}$ & $17 \pm 5^{*}$ & $-22 \pm 61^{*}$ \\
\hline BJP3 & 0.01 & 7 & $19.5 \pm 0.8$ & $1,534 \pm 169$ & $63 \pm 5$ & $78 \pm 5$ \\
\hline ATF & & & $20.2 \pm 0.9$ & $1,713 \pm 122$ & $67 \pm 5$ & $72 \pm 7$ \\
\hline BJP3 & 1 & 5 & $19.3 \pm 0.6$ & $1,476 \pm 150$ & $60 \pm 6$ & $81 \pm 7$ \\
\hline ATF & & & $21.4 \pm 0.9$ & $1,985 \pm 127$ & $74 \pm 3$ & $63 \pm 6$ \\
\hline$\Delta$ & & & & $-509 \pm 157^{*}$ & $-14 \pm 3^{*}$ & $18 \pm 4^{*}$ \\
\hline BJP3 & 50 & 6 & $20.3 \pm 1.1$ & $1,372 \pm 118$ & $52 \pm 4$ & $80 \pm 4$ \\
\hline ATF & & & $21.1 \pm 0.5$ & $1,795 \pm 75$ & $66 \pm 3$ & $71 \pm 4$ \\
\hline$\Delta$ & & & & $-423 \pm 104^{*}$ & $-14 \pm 3^{*}$ & $9 \pm 3^{*}$ \\
\hline MYG & 50 & 5 & $21.3 \pm 0.6$ & $1,465 \pm 139$ & $46 \pm 4$ & $90 \pm 4$ \\
\hline ATF & & & $21.4 \pm 0.7$ & $1,839 \pm 120$ & $66 \pm 5$ & $73 \pm 9$ \\
\hline$\Delta$ & & & & $-374 \pm 88^{*}$ & $-20 \pm 7^{*}$ & $16 \pm 6^{*}$ \\
\hline
\end{tabular}

$n$, number of animals; $\Delta$, mean differences between control and experimental values. $\quad * P<0.05$, compared with controls. 

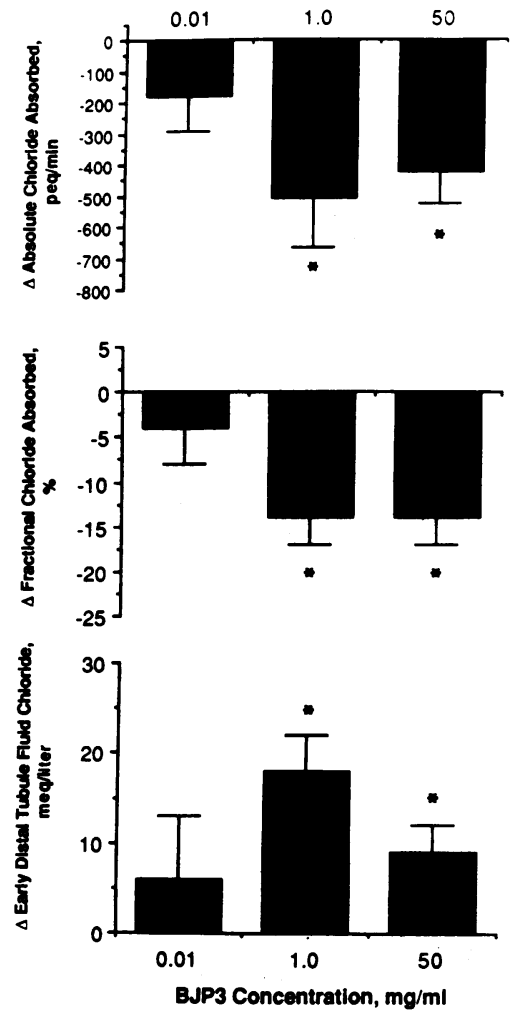

Figure 1. Effect of various concentrations of BJP3 on chloride absorption in the LS. Perfusion duration was $<2$ min. A concentrationdependent decrease in absolute and fractional chloride absorption and ED chloride was observed, inasmuch as the alterations in these values did not reach statistical significance with BJP3, $0.01 \mathrm{mg} / \mathrm{ml}$. ${ }^{*} P$ $<0.05$, compared with corresponding control perfusions.

Turbidity measurements. No change in turbidity was noted in solutions of increasing $[\mathrm{NaCl}]$ containing the test proteins alone, THP alone, and THP with ALB or BLG. The other LMWPs, LYZ, BJP1, BJP2, BJP3, and cationic ALB, aggregated with THP as manifested by an increase in the turbidity of these solutions. When [ $\mathrm{NaCl}]$ was $>80 \mathrm{mM}$, turbidity of solutions containing THP and LYZ, BJP1, BJP2, or BJP3 increased (Fig. 2). Although MYG was not examined with this system, a visible precipitate developed with the addition of MYG to those THP solutions that had $[\mathrm{NaCl}]>80 \mathrm{mM}$. Coprecipitation of the test LMWP with THP was related to $\mathrm{pI}$ of the LMWP, because no change in turbidity occurred when the pI was $<5.2$. Those proteins with the highest pIs tended to produce the greatest percent increase in turbidity (Fig. 2). Cationic ALB, which had a pI of 9.2, dramatically aggregated with THP (Fig. 3). Addition of the LMWPs did not change the final

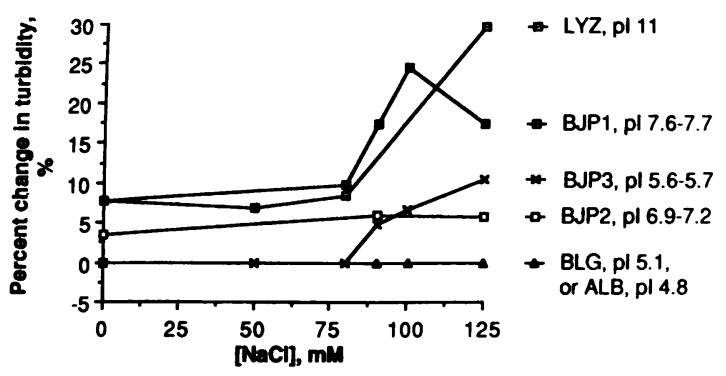

Figure 2. Influence of $[\mathrm{NaCl}]$ on aggregation of THP with six different proteins in vitro. As [ $\mathrm{NaCl}]$ increased to $>80 \mathrm{mM}$, turbidity of solutions containing THP and LYZ, BJP1, BJP2, or BJP3 increased. Solutions containing the more cationic proteins tended to produce greater changes in turbidity. No change in turbidity was noted in solutions with proteins that had pIs $<5.2$ (ALB and BLG).

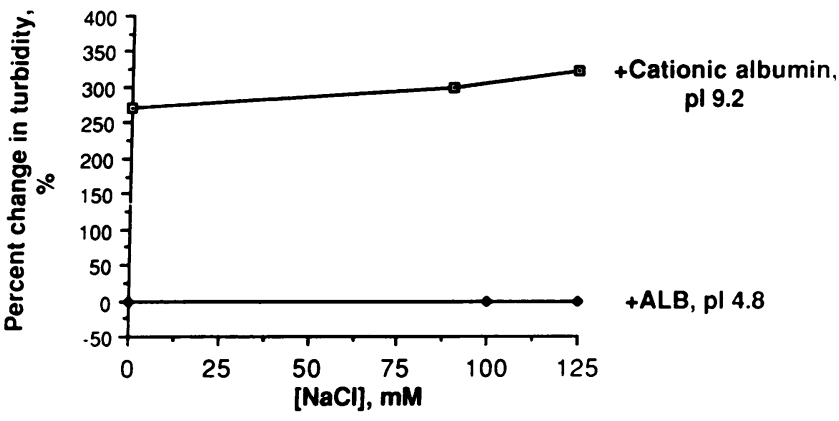

Figure 3. Comparison of change in turbidity of solutions of cationic ALB, pI 9.2, to ALB, pI 4.8. A dramatic increase in turbidity of the cationic ALB solutions was observed at all [ $\mathrm{NaCl}]$, compared with the ALB solutions. Turbidity of the cationic ALB solution increased as $[\mathrm{NaCl}]$ increased.

$\mathrm{pH}$ of the solution. [ $\left.\mathrm{CaCl}_{2}\right], 2$ and $4 \mathrm{mM}$, increased turbidity of THP/BJP1 solutions (Fig. 4), but $\left[\mathrm{MgCl}_{2}\right], 2$ or $4 \mathrm{mM}$, had no effect on turbidity.

Dynamic light scattering. The results of light scattering were complementary with the turbidity measurements. The solutions that were used included THP alone, test proteins (ALB, LYZ, BJP1, and BJP3) alone, and THP combined with the test proteins. Aggregation of LYZ, BJP1, and BJP3 with THP was demonstrated by an increase in $d$ and decrease in the $D_{t}$ of the macromolecules in those protein solutions (Table II). These values increased when $[\mathrm{NaCl}]$ of these solutions was $>80 \mathrm{mM}$. In addition, with this sensitive technique, THP alone exhibited an increase in $d$ and decrease in $D_{t}$ when $[\mathrm{NaCl}]>80 \mathrm{mM}$. ALB $(8.9 \mu \mathrm{M})$ was present in significantly higher concentration than THP $(1.0 \mu \mathrm{M})$ and has a much smaller Stokes radius; these factors produced the very small $d$ and $D_{t}$, compared with the other protein solutions. Neither of these parameters changed in relation to $[\mathrm{NaCl}]$ in those solutions that contained LMWPs alone or THP plus ALB.

\section{Discussion}

We have shown that: (a) LMWP (certain BJPs [BJP2 and BJP3] and MYG) that produced distal nephron proteinaceous casts in vivo in the rat (8) aggregated with human THP in vitro, whereas those proteins (ALB and BLG) that had not been shown to precipitate significantly in vivo (8) did not interact with THP in vitro in these studies; $(b)$ aggregation was influenced by the pI of the LMWP, since test proteins with pIs $>5.1$ and cationic ALB, pI 9.2, precipitated with THP in vitro; (c) increasing $[\mathrm{NaCl}]$ or $\left[\mathrm{CaCl}_{2}\right]$, but not magnesium chloride, within the physiologic concentration range found in the LS

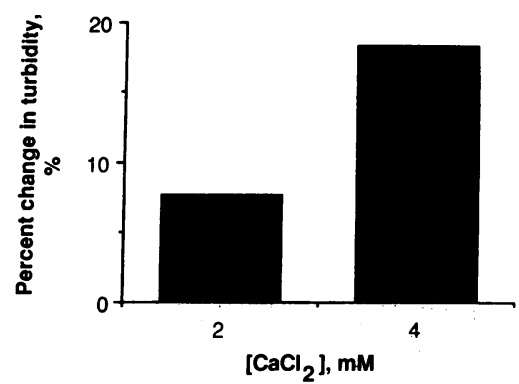

Figure 4. Effect of physiologic concentrations of $\mathrm{CaCl}_{2}$ on turbidity of solutions containing THP and BJP1. Turbidity was augmented with increasing $\left[\mathrm{CaCl}_{2}\right]$. 
Table II. Results of Dynamic Light Scattering

\begin{tabular}{lrcc}
\hline \multicolumn{1}{c}{ Solution } & {$[\mathrm{NaCl}]$} & Mean diameter & $\begin{array}{c}\text { Mean diffusion coefficient } \\
\times 10^{7}\end{array}$ \\
\hline & $m M$ & $n m$ & $\mathrm{~cm}^{2}$ \\
THP alone & 0 & $122 \pm 1$ & $0.16 \pm 0.00$ \\
& 80 & $128 \pm 4$ & $0.19 \pm 0.02$ \\
THP + BJP1 & 125 & $264 \pm 10^{*}$ & $0.09 \pm 0.01^{*}$ \\
& 0 & $166 \pm 19$ & $0.13 \pm 0.02$ \\
THP + BJP3 & 80 & $101 \pm 18$ & $0.16 \pm 0.02$ \\
& 125 & $404 \pm 14^{*}$ & $0.04 \pm 0.00^{*}$ \\
THP + ALB & 0 & $123 \pm 1$ & $0.28 \pm 0.00$ \\
& 125 & $109 \pm 2$ & $0.29 \pm 0.01$ \\
& 0 & $140 \pm 8^{*}$ & $0.22 \pm 0.02^{*}$ \\
THP + LYZ & 80 & $12 \pm 1$ & $1.82 \pm 0.32$ \\
& 125 & $14 \pm 1$ & $2.19 \pm 0.36$ \\
& 0 & $2,550 \pm 150$ & $1.60 \pm 0.25$ \\
& 80 & TLTM & $0.01 \pm 0.00$ \\
& 125 & TLTM & UTC \\
& & & UTC \\
\hline
\end{tabular}

TLTM, too large to measure (exceeds capability of the system); UTC, unable to calculate.

${ }^{*} P<0.05$, compared with either 0 or $80 \mathrm{mM}[\mathrm{NaCl}]$.

(26-31), produced or enhanced aggregation of THP with certain proteins; and $(d)$ perfusion of the LS with LMWPs (BJP3 and MYG) that precipitated in vivo (8) decreased chloride absorption and elevated $\mathrm{ED}\left[\mathrm{Cl}^{-}\right]$, whereas non-cast-forming proteins (ALB and BJP1) actually lowered ED [Cl-].

These findings were compared with data obtained from previous work (8) using these proteins (Table III). Cast-forming proteins aggregated with THP in vitro and also decreased chloride absorption by the $\mathrm{LS}$ in vivo, which elevated $\mathrm{ED}\left[\mathrm{Cl}^{-}\right]$ and facilitated aggregation (as demonstrated in vitro). In contrast, the non-cast-forming proteins either did not interact with THP (e.g., ALB and BLG) or lowered ED $\left[\mathrm{Cl}^{-}\right]$, which diminished aggregation with THP, as shown in vitro with BJP1. Taken together, the results using these proteins demonstrated that aggregation with THP and altered LS function were independent events that participated in the formation of LMWP casts in the distal nephron (Table III).

Table III. Summary of the Effects of Five Nephrotoxic LMWP and Albumin

\begin{tabular}{lccccc}
\hline Protein & Isotype & pI & $\begin{array}{c}\text { LS chloride } \\
\text { absorption } \\
\text { in vivo }\end{array}$ & $\begin{array}{c}\text { Luminal } \\
\text { precipitation } \\
\text { in vivo* }\end{array}$ & $\begin{array}{c}\text { Aggregation } \\
\text { with THP } \\
\text { in vitro }\end{array}$ \\
\hline ALB & - & 4.8 & $\uparrow$ & 0 & 0 \\
BJP1 & $\kappa$ & $7.6-7.7$ & $\uparrow$ & 0 & +++ \\
BJP2 & $\kappa$ & $6.9-7.2$ & ND & +++ & ++ \\
BJP3 & $\lambda$ & $5.6-5.7$ & $\downarrow$ & +++ & +++ \\
BLG & - & 5.1 & ND & $0 /+$ & 0 \\
MYG & - & 7.3 & $\downarrow$ & +++ & +++
\end{tabular}

* These observations were published in Reference 8, except for albumin, which represented unpublished observations from our laboratory.
An important role of THP in formation of distal nephron casts of LMWPs has been postulated $(2,3,9-11,15,16)$. This glycoprotein has been shown to be a secretory product of cells of the TALH and early distal convoluted tubule (16) and the major constituent of casts in urine $(16,32)$. Several studies $(2$, $3,9-11,16$ ) have demonstrated THP in distal nephron casts of patients with cast nephropathy from Bence Jones proteinuria. In addition, coprecipitation of human THP with hemoglobin, MYG, and two unique human BJPs has been shown to occur in vitro (15). Decreasing the $\mathrm{pH}$ of the solution and, to a lesser extent, increasing the concentration of LMWP, enhanced precipitation (15). Stevenson et al. (33), demonstrated that when the $[\mathrm{NaCl}]$ of THP-containing solutions was $>60 \mathrm{mM}$, the viscosity of the solutions dramatically increased. Increasing the concentration of THP $(33-35),\left[\mathrm{H}^{+}\right](34,35)$, and $\left[\mathrm{Ca}^{2+}\right]$ (33) also increased viscosity of THP-containing solutions, whereas $\left[\mathrm{Mg}^{2+}\right]$ within the physiologic range in the $\operatorname{LS}(29,30)$ had no effect on viscosity (33). Our light-scattering data using solutions of THP alone corroborated the finding of increasing size of THP with increasing $[\mathrm{NaCl}]$ within the physiologic range seen in the TALH (26-28). Electron microscopic examination of THP solutions confirmed lateral association of the filamentous molecules of THP in concentrated salt solutions (36) and thus provided morphologic correlation of these viscometric and light-scattering observations. Since the test proteins were not affected by the $[\mathrm{NaCl}]$ or $\left[\mathrm{CaCl}_{2}\right]$ of the solution alone, increasing the size and molecular form of THP allowed this protein to serve as a nidus upon which LMWPs with pI $>5.1$ aggregated.

The mechanism by which aggregation of THP with LMWPs occurs in the presence of $\mathrm{NaCl}$ is unknown. In neutral solution, THP, which has a pI of 3.5 (15), and those LMWPs with $\mathrm{pI}<7$ (ALB, BLG, BJP2, and BJP3) have net negative charges. Thus, aggregation of THP with these proteins is unlikely because of the net electrostatic repulsion. In the presence of increasing $[\mathrm{NaCl}]$, however, individual positive and negative charges in these proteins are increasingly shielded by the electrolyte ions. This shielding should reduce net electrostatic repulsion and promote interaction between the molecules of THP as well as these acidic proteins. Aggregation occurred between THP and BJP2 and BJP3 in $\mathrm{NaCl}$, although not with ALB and BLG, which had the lowest pIs (Fig. 2). The cationic LMWPs (BJP1, LYZ, and cationic ALB) carry net positive charges at $\mathbf{p H}$ 7.0. These proteins can interact electrostatically with the negatively charged THP even in the absence of $\mathrm{NaCl}$. Indeed, an increase in baseline turbidity of these solutions of THP and cationic proteins was observed in the absence of $\mathrm{NaCl}$ (Figs. 2 and 3). Addition of $\mathrm{NaCl}$ to these solutions is expected to partially shield individual charges, leading to a decrease in electrostatic interaction with THP. Also, since the turbidity of the solutions of THP and cationic ALB was considerably greater than that observed with any of the other proteins, it appears that two types of interaction may be responsible for the aggregation of THP with LMWPs. In low [ $\mathrm{NaCl}]$, the interaction was predominantly electrostatic. Increasing $[\mathrm{NaCl}]$ diminished electrostatic interactions, allowing a second and strong interaction to promote aggregation of THP with the proteins. This study does not provide further insight into the nature of this second interaction.

Our data demonstrated an integral role of altered LS function in luminal precipitation of LMWPs and subsequent cast formation in the distal nephron. This alteration occurred 
within 2 min of contact time with the test protein and before the development of casts, which were shown to be absent with dissection of the perfused nephrons. Preventing the normal process of $\mathrm{NaCl}$ absorption in the LS has been shown to decrease the absorption of calcium in the TALH and early distal convoluted tubule (29-31). By elevating luminal $\left[\mathrm{Cl}^{-}\right]$and probably both $\left[\mathrm{Na}^{+}\right]$and $\left[\mathrm{Ca}^{2+}\right]$ in the critical segments of the nephron that secreted THP, cast-forming LMWPs (BJP3 and MYG) thus promoted their aggregation with THP. Another LMWP (BJP1), which did not precipitate in the rat nephron in vivo (8), actually augmented chloride absorption in the LS and decreased luminal $\left[\mathrm{Cl}^{-}\right]$, thereby diminishing aggregation with THP. The finding that certain BJPs produced LS dysfunction also provided an explanation for the clinical observation that patients who had multiple myeloma, renal failure, and Bence Jones proteinuria were unable to concentrate their urine as well as patients who had myeloma and similar degrees of renal failure but no BJP in the urine (37).

Since altered LS function and aggregation with THP did not coincide among the LMWPs that were tested (Table III), these independent events were related to different physicochemical properties of the LMWPs. Unlike aggregation, which was related to the pI of the LMWP, no relationship between LS alteration and pI was apparent. Alteration of LS function was related to the concentration of the LMWP (Fig. 1), but not to isotype or molecular form. The physicochemical property that conferred this ability to alter LS function was not determined. Thus, pI plus another, as yet unidentified, physicochemical property of LMWPs produced cast formation. These findings also explain the discrepancy in the literature (10) regarding the correlation between pI of BJP and clinical renal failure, because two properties of the LMWP were important determinants of protein precipitation.

To the extent that these results can be extrapolated to humans, LMWP nephrotoxicity from protein cast formation in the distal nephron is related to aggregation of the LMWPs with THP. This aggregation is a function of the luminal concentration and $\mathrm{pI}$ of the LMWP and the environment in which these proteins interact. Luminal $[\mathrm{NaCl}],\left[\mathrm{Ca}^{2+}\right]$, and $\left[\mathrm{H}^{+}\right]$in the distal nephron, the site of THP secretion (16), are important because increasing the concentrations of these ions increases the molecular size and form of THP, providing the nidus for aggregation with LMWP. Because some, but not all, LMWPs can alter chloride absorption in the LS, this physiological alteration becomes a major determinant of cast formation, occasionally militating against the contributory effect of the cationic charge of the LMWP. For example, BJP1, with a pI of 7.6-7.7, aggregated with THP in vitro, but increased chloride absorption and decreased chloride concentration of ED and did not precipitate and obstruct the rat nephron in vivo (8). Inasmuch as ALB enhanced chloride absorption in the LS, an effect opposite that of cast-forming LMWPs, which decreased chloride absorption, ALB could potentially antagonize the formation of casts of LMWP. Clinically, despite the presence of Bence Jones proteinuria, glomerular lesions from light-chain deposition have not generally occurred with distal nephron cast formation (38), perhaps related to concomitant albuminuria. Augmented LS chloride absorption from albuminuria might also partially explain the renal sodium avidity of patients with nephrotic syndrome.

Other factors such as hypercalcemia and loop diuretics alter chloride absorption in the LS and can thus affect cast formation. Hypercalcemia has been shown to decrease LS chloride absorption $(31,39)$, which increases luminal $\left[\mathrm{Na}^{+}\right]$, $\left[\mathrm{Ca}^{2+}\right]$, and $\left[\mathrm{Cl}^{-}\right]$in the distal nephron, and can cause intravascular volume depletion. These effects facilitate aggregation of certain LMWPs with THP and could, therefore, precipitate cast formation and renal failure. Indeed, hypercalcemia can initiate renal failure in patients with multiple myeloma and Bence Jones proteinuria (40). Furosemide is another agent that alters $\mathrm{LS}$ function. This loop diuretic increases luminal $[\mathrm{NaCl}]$ and produces calciuria (41). In addition, furosemide has been shown to increase THP secretion in slices of rat kidney cortex in vitro (42). Thus, loop diuretics, despite the potential benefit of increasing tubule fluid flow rate, could aggravate cast nephropathy in susceptible patients with Bence Jones proteinuria when the pI of the LMWP is > 5.1, especially in the setting of volume depletion.

In conclusion, our data using eight different proteins demonstrate that cast formation, which is a major cause of clinical renal failure from LMWPs, occurred because of aggregation of the LMWP with THP. Aggregation was related to the pI of the LMWP and the electrolyte composition of the surrounding milieu. LMWPs destined to form casts altered LS function that increased tubule fluid chloride concentration, promoting aggregation of THP and subsequent coprecipitation with the LMWP. It should be noted that only four proteins were used in these LS studies. Thus, other as yet unidentified variables may also play a role in cast formation. These findings provide insight into several clinical observations of LMWP nephrotoxicity in humans and present new concepts potentially useful in the management of patients who have myoglobinuria or Bence Jones proteinuria.

\section{Acknowledgments}

The authors thank Dr. David G. Warnock and Dr. John R. Hoyer for their support and helpful suggestions, the Media Service of the Veterans Administration and Ms. Ellen Bernstein for the illustrations, and Ms. Carol A. Peterson for secretarial assistance.

This work was supported by the Research Service of the Veterans Administration with Merit and Career Development Awards and a biomedical research support grant from the University of Alabama at Birmingham. Dr. Sanders is a Research Associate of the Veterans Administration.

\section{References}

1. Herrera, G. A., P. W. Sanders, R. L. Lott, and J. H. Galla. 1988. The value of IF, EM, and ultrastructural immunolabeling (UIL) in the identification of early and unusual morphologic manifestations of monoclonal light chain-related renal disease (LCRRD). Lab. Invest. 58:38A. (Abstr.)

2. Pirani, C. L., F. Silva, V. D'Agati, P. Chander, and L. M. M Striker. 1987. Renal lesions in plasma cell dyscrasias: ultrastructural observations. Am. J. Kidney Dis. 10:208-221.

3. Cohen, A. H., and W. A. Border. 1980. Myeloma kidney. An immunomorphogenetic study of renal biopsies. Lab. Invest. 42:248256.

4. Mason, J., C. Olbricht, T. Takabatake, and K. Thurau. 1977. The early phase of experimental acute renal failure. I. Intratubular pressure and obstruction. Pfluegers Arch. Eur. J. Physiol. 370:155163.

5. Zager, R. A., and L. M. Gamelin. 1989. Pathogenetic mechanisms in experimental hemoglobinuric acute renal failure. $\mathrm{Am}$. J. Physiol. 256:F446-F455. 
6. Sanders, P. W., G. A. Herrera, and J. H. Galla. 1987. Human Bence Jones protein toxicity in rat proximal tubule epithelium in vivo. Kidney Int. 32:851-861.

7. Sanders, P. W., G. A. Herrera, R. L. Lott, and J. H. Galla. 1988. Morphologic alterations of the proximal tubules in light chain-related renal disease. Kidney Int. 33:881-889.

8. Sanders, P. W., G. A. Herrera, A. Chen, B. B. Booker, and J. H. Galla. 1988. Differential nephrotoxicity of low molecular weight proteins including Bence Jones proteins in the perfused rat nephron in vivo. J. Clin. Invest. 82:2086-2096.

9. Pirani, C. L., F. G. Silva, and G. B. Appel. 1983. Tubulo-interstitial disease in multiple myeloma and other nonrenal neoplasias. In Tubulo-interstitial Nephropathies. R. S. Cotran, B. M. Brenner, and J. H. Stein, editors. Churchill-Livingstone Inc., New York. 287-334.

10. Smolens, P. 1987. The kidney in dysproteinemic states. $A K F$ Nephrology Letter. 4:27-42.

11. Silva, F. G. 1982. The kidney in plasma cell dyscrasias: a review and a clinicopathologic study of 50 patients. In Progress in Surgical Pathology. C. E. Fenoglio and M. Wolff, editors. Masson Publishing USA, Inc., New York. 131-176.

12. McIntire, K. R., and M. Potter. 1964. Studies of thirty different Bence Jones protein-producing plasma cell neoplasms in an inbred strain of mouse. J. Natl. Cancer Inst. 33:631-639.

13. Koss, M. N., C. L. Pirani, and E. F. Osserman. 1976. Experimental Bence Jones cast nephropathy. Lab. Invest. 34:579-591.

14. Weiss, J. H., R. H. Williams, J. H. Galla, J. L. Gottschall, E. D. Rees, D. Bhathena, and R. G. Luke. 1981. Pathophysiology of acute Bence Jones protein nephrotoxicity in the rat. Kidney Int. 20:198-210.

15. Pesce, A. J., D. H. Clyne, V. E. Pollak, and S. K. Kant. 1980. Renal tubular interactions of proteins. Clin. Biochem. 13:209-215.

16. Hoyer, J. R., and M. W. Seiler. 1979. Pathophysiology of Tamm-Horsfall protein. Kidney Int. 16:279-289.

17. Tamm, I., and F. L. Horsfall, Jr. 1950. Characterization and separation of an inhibitor of viral hemagglutination present in urine. Proc. Soc. Exp. Biol. Med. 74:108-114.

18. Laemmli, U. K. 1970. Cleavage of structural proteins during the assembly of the head of bacteriophage T4. Nature (Lond.). 227:680-685.

19. Sanders, P. W., J. E. Volanakis, S. G. Rostand, and J. H. Galla. 1986. Human complement protein $D$ catabolism by the rat kidney. $J$. Clin. Invest. 77:1299-1304.

20. Booker, B. B., R. H. Williams, and R. G. Luke. 1983. Effect of volume expansion and plasma chloride on function of the loop segment. Am. J. Physiol. 245:F41-F47.

21. Carlson, F. D. 1975. The application of intensity fluctuation spectroscopy to molecular biology. Annu. Rev. Biophys. Bioeng. 4:243-264.

22. Pecora, R., editor. 1985. Dynamic Light Scattering Applications of Photon Correlation Spectroscopy. Plenum Publishing Corp., New York. 346-354.

23. Brown, J. C., P. N. Pusey, and R. Dietz. 1975. Photon correlation study of polydisperse samples of polystyrene in cyclohexane. $J$. Chem. Phys. 62:1136-1144.
24. Stock, R. S., and W. H. Ray. 1985. Interpretation of photon correlation spectroscopy data: a comparison of analysis methods. $J$. Polym. Sci. Polym. Phys. Ed. 23:1393-1447.

25. Tanford, C. 1976. Physical Chemistry of Macromolecules. John Wiley \& Sons, New York. 346-364.

26. Gelbart, D. R., C. A. Battilana, J. Bhattacharya, F. B. Lacy, and R. L. Jamison. 1978. Transepithelial gradient and fractional delivery of chloride in thin loop of Henle. Am. J. Physiol. 235:F192-F198.

27. Hogg, R. J., and J. P. Kokko. 1978. Comparison between the electrical potential profile and the chloride gradients in the thin limbs of Henle's loop in rats. Kidney Int. 14:428-436.

28. Jamison, R. L. 1983. The renal concentrating mechanism: micropuncture studies of the renal medulla. Fed. Proc. 42:2392-2397.

29. Quamme, G. A. 1981. Effect of furosemide on calcium and magnesium transport in the rat nephron. Am. J. Physiol. 241:F340F347.

30. Quamme, G. A. 1989. Control of magnesium transport in the thick ascending limb. Am. J. Physiol. 256:F197-F210.

31. Agus, Z. S., and S. Goldfarb. 1985. Calcium metabolism: normal and abnormal. In Fluid, Electrolyte, and Acid-Base Disorders. A. I. Arieff and R. A. DeFronzo, editors. Churchill-Livingstone Inc., New York. 511-573.

32. McQueen, E. G. 1962. The nature of urinary casts. J. Clin. Pathol. (Lond.). 15:367-373.

33. Stevenson, F. K., A. J. Cleave, and P. W. Kent. 1971. The effect of ions on the viscometric and ultracentrifugal behaviour of TammHorsfall glycoprotein. Biochim. Biophys. Acta. 236:59-66.

34. McQueen, E. G., and G. B. Engel. 1966. Factors determining the aggregation of urinary mucoprotein. J. Clin. Pathol. (Lond.). 19:392-396.

35. Curtain, C. C. 1953. The viscometric behaviour of a mucoprotein isolated from human urine. Aust. J. Exp. Biol. Med. Sci. 31:255266.

36. Porter, K. R., and I. Tamm. 1954. Direct visualization of a mucoprotein component of urine. J. Biol. Chem. 212:135-140.

37. DeFronzo, R. A., C. R. Cooke, J. R. Wright, and R. L. Humphrey. 1978. Renal function in patients with multiple myeloma. Medicine (Baltimore). 57:151-166.

38. Hill, G. S., L. Morel-Maroger, J.-P. Méry, J. C. Brouet, and F. Mignon. 1983. Renal lesions in multiple myeloma: their relationship to associated protein abnormalities. Am. J. Kidney Dis. 2:423-438.

39. Galla, J. H., B. B. Booker, and R. G. Luke. 1986. Role of the loop segment in the urinary concentrating defect of hypercalcemia. Kidney Int. 29:977-982.

40. DeFronzo, R. A., R. L. Humphrey, J. R. Wright, and C. R. Cooke. 1975. Acute renal failure in multiple myeloma. Medicine (Baltimore). 54:209-223.

41. Quamme, G. A. 1986. Loop diuretics. In Diuretics: Physiology, Pharmacology and Clinical Use. J. H. Dirks and R. A. L. Sutton, editors. W. B. Saunders Co., Philadelphia. 86-116.

42. Wirdnam, P. K., and R. D. G. Milner. 1984. Tamm-Horsfall glycoprotein release from rat kidney cortex slices in vitro. Clin. Sci. (Lond.). 67:529-534. 